\title{
Percutaneous instrumentation with cement augmentation for traumatic hyperextension thoracic and lumbar fractures in ankylosing spondylitis: a single-institution experience
}

\author{
Sokol Trungu, MD, PhD, 1,2 Luca Ricciardi, MD,1,2 Stefano Forcato, MD,1 \\ Massimo Miscusi, MD, $\mathrm{PhD},{ }^{2}$ and Antonino Raco, MD, $\mathrm{PhD}^{2}$ \\ ${ }^{1}$ Neurosurgery Unit, Cardinale G. Panico Hospital, Tricase; and 2NESMOS Department, "Sapienza" University of Rome, \\ Sant'Andrea Hospital, Rome, Italy
}

OBJECTIVE The typical traumatic thoracolumbar (TL) fracture in patients with ankylosing spondylitis (AS) is a hyperextension injury involving all three spinal columns, which is associated with unfavorable outcomes. Although a consensus on the management of these highly unstable injuries is missing, minimally invasive surgery (MIS) has been progressively accepted as a treatment option, since it is related to lower morbidity and mortality rates. This study aimed to evaluate clinical and radiological outcomes after percutaneous instrumentation with cement augmentation for hyperextension $\mathrm{TL}$ fractures in patients with AS at a single institution.

METHODS This cohort study was completed retrospectively. Back pain was assessed at preoperative, postoperative, and final follow-up visits using the visual analog scale (VAS). Patient-reported outcomes via the Oswestry Disability Index (ODI) and the new mobility score (NMS) were obtained to assess disability and mobility during follow-up. Radiological outcomes included the Cobb angle, sagittal index (SI), union rate, and implant failure. Intra- and postoperative complications were recorded.

RESULTS A total of 22 patients met inclusion criteria. The mean patient age was $74.2 \pm 7.3$ years with a mean follow-up of $39.2 \pm 17.4$ months. The VAS score for back pain significantly improved over the follow-up period (from $8.4 \pm 1.1$ to $2.8 \pm 0.8, p<0.001$ ). At the last follow-up, all patients had minor disability (mean ODI score $24.4 \pm 6.1, p=0.003$ ) and self-sufficiency of mobility (mean NMS $7.5 \pm 1.6, p=0.02)$. The Cobb angle $\left(5.2^{\circ} \pm 2.9^{\circ}\right.$ preoperatively to $4.4^{\circ} \pm 3.3^{\circ}$ at follow-up) and $\mathrm{SI}\left(7.9^{\circ} \pm 4.2^{\circ}\right.$ to $\left.8.8^{\circ} \pm 5.1^{\circ}\right)$ were maintained at follow-up, showing no loss of segmental kyphosis. Bone union was observed in all patients. The overall complication rate was $9.1 \%$, while the reoperation rate for implant failure was $4.5 \%$.

CONCLUSIONS Percutaneous instrumentation with cement augmentation for traumatic hyperextension TL fractures in AS demonstrated good clinical and radiological outcomes, along with a high bone union level and low reoperation rate. Accordingly, MIS reduced the complication rate in the management of these injuries of the ankylosed spine.

https://thejns.org/doi/abs/10.3171/2021.7.FOCUS21308

KEYWORDS ankylosing spondylitis; thoracolumbar fractures; percutaneous pedicle screw fixation; spinal ankylosing disorder; minimally invasive surgery; cement augmentation

$\mathrm{A}$ NKYLOSING spondylitis (AS) is a progressive chronic inflammatory disorder that affects mostly the axial skeleton and paraspinal soft tissue, which leads to a pathological remodeling and rigidity of the spine. ${ }^{1}$ Its overall prevalence is estimated to be between $0.1 \%$ and $1.4 \%$, and males are affected twice as often as females. ${ }^{2,3}$ Additionally, AS is associated with osteoporosis and a prevalence between $19 \%$ and $61 \%$ has been reported. ${ }^{4}$ Both factors increase the risk of vertebral fractures, which usually affect all three columns of the spine and can occur even under low-energy trauma. Moreover, patients with AS have a fourfold increased risk of fractures compared with the typical population, especially in advanced disease. $^{5}$

ABBREVIATIONS AS = ankylosing spondylitis; ASA = American Society of Anesthesiologists; $A$ SIA = American Spinal Injury Association; CCI = Charlson Comorbidity Index; MIS = minimally invasive surgery; NMS = new mobility score; ODI = Oswestry Disability Index; SI = sagittal index; TL = thoracolumbar; VAS = visual analog scale. SUBMITTED June 1, 2021. ACCEPTED July 16, 2021.

INCLUDE WHEN CITING DOI: 10.3171/2021.7.FOCUS21308. 
Thoracolumbar (TL) hyperextension fractures (type B3, AO Spine Thoracolumbar Spine Injury Classification System $^{6}$ ) are mainly restricted to patients affected with ankylosing spinal disorders and represent $20 \%$ to $40 \%$ of AS fractures. 7 Although nonoperative treatment has been reported, it is ineffective in most patients, with a high failure rate of almost $50 \%$ of ankylosed spine injuries. ${ }^{8,9}$

Typically, the surgical treatment of TL fractures involves open posterior instrumentation. ${ }^{10-12}$ However, it is related to high postoperative mortality and morbidity rates. ${ }^{13,14}$ Recently, minimally invasive surgery (MIS) has been progressively accepted as a treatment option by ensuring the stability of the spine while limiting the risk of complications. ${ }^{15-17}$ However, the surgical management of these highly unstable injuries remains to be clarified.

The aim of this study was to evaluate the clinical and radiological outcomes of percutaneous instrumentation with cement augmentation for traumatic hyperextension TL fractures in patients with AS at a single institution.

\section{Methods \\ Study Design}

This is a retrospective cohort study from a single institution. According to the study design and national and institutional guidelines, ethics committee approval was not required. At the time of hospitalization, all patients provided their written informed consent for surgery and data management for scientific purposes. This study complies with the World Medical Association Declaration of Helsinki.

\section{Patient Population}

Patients admitted at our tertiary academic referral center for traumatic TL fractures who underwent percutaneous instrumentation between December 2014 and December 2019 (5 years) were considered for eligibility. Inclusion criteria were a diagnosis of AS based on the modified New York criteria, ${ }^{18}$ traumatic hyperextension TL fractures (B3 type) classified according to the AO Spine Thoracolumbar Spine Injury Classification System, and follow-up > 12 months. Exclusion criteria were incomplete clinical and radiological data, previous TL surgery, nontraumatic fractures, and $<12$ months of follow-up.

\section{Surgical Technique}

The patient is positioned prone on a radiolucent table under general anesthesia. Anteroposterior and laterolateral views on radioscopic fluoroscopy are used for intraoperative guidance. The pedicles of the target vertebrae are first visualized, and the skin entry point is marked $1 \mathrm{~cm}$ lateral to the pedicle projection. Subsequently, Jamshidi needles, guide wires, and screws are inserted percutaneously using the standard technique. A convergent and straightforward pedicle screw trajectory is preferred. After placement of all screws, cement augmentation is performed in all patients. At the end of the procedure, contouring of the rods is performed, and these are inserted and locked in place.

Patients were treated with long-segment fixation (8 screws) using an instrumentation system involving two vertebrae above and two below the fractured vertebra. In addition, a posterior mini-open decompression was performed in 8 patients with neurological deficits. Screw sizes ranged in length and diameter from $30 \mathrm{~mm}$ to $55 \mathrm{~mm}$ and from $4.5 \mathrm{~mm}$ to $7.5 \mathrm{~mm}$, respectively. Different percutaneous instrumentation systems were used over the years. Bracing was never prescribed after surgery in any case.

\section{Clinical Outcomes}

General and clinical conditions, as well as quality of life, were evaluated at admission (preoperative parameters), and postoperatively at 6-week, 1-year, and final follow-up visits, using a 10-point itemized visual analog scale (VAS) for back pain and the American Spinal Injury Association (ASIA) impairment scale for neurological examination. Patient-reported outcomes were evaluated at the 6-week, 1-year, and final follow-up visits to assess disability using the Oswestry Disability Index (ODI) score and to assess mobility using the new mobility score (NMS) as described by Parker and Palmer (a score of 0 indicates the impossibility of mobilizing independently, while a maximum score of 9 indicates a completely independent state of mobility). ${ }^{19}$ Trauma types and mechanisms (low- or high-energy trauma) were recorded, and intra- and postoperative complications were collected.

\section{Radiological Outcomes}

Preoperative radiographs and CT scans were retrieved from the institutional PACS. Preoperative MRI was performed only in cases of neurological deficit. The following radiological parameters were evaluated on CT scans: the Cobb angle, as the angle between a line drawn parallel to the superior end plate of one vertebra above the fracture and a line drawn parallel to the inferior end plate of the vertebra one level below the fracture ${ }^{20}$ and the sagittal index (SI), as the measurement of segmental kyphosis at the level of a mobile segment (1 vertebra and 1 disc) adjusted for the baseline sagittal contour at that level. ${ }^{21}$

Screw misplacement was evaluated on a postoperative CT scan and classified according to the grading system of Gertzbein and Robbins. ${ }^{22}$ Bone formation on the CT scan was considered a criterion for bone union. The presence of screw breakage, screw pullout, peri-implant loosening, and rod breakage were considered as criteria for implant failure.

\section{Statistical Analysis}

Values are reported as mean \pm standard deviation. The Student t-test was used to compare the quantitative continuous variables. The Fisher's exact test (2-sided) was used instead to compare the categorical variables. Statistical significance was predetermined at $\mathrm{p}<0.05$. SPSS Statistics version 14.0 (SPSS Inc.) was used for data analysis.

\section{Results}

\section{Patient and Operative Characteristics}

A total of 22 patients with AS and traumatic hyperextension TL fractures (type B3) who underwent percutaneous instrumentation during the study period were included for data analysis. 
TABLE 1. Patient characteristics

\begin{tabular}{|c|c|}
\hline & Value \\
\hline Mean age, yrs & $74.2 \pm 7.3(62-84)$ \\
\hline Mean follow-up, mos & $39.2 \pm 17.4(14-65)$ \\
\hline \multicolumn{2}{|l|}{ Sex } \\
\hline $\mathrm{F}$ & $7(31.8)$ \\
\hline M & $15(68.2)$ \\
\hline \multicolumn{2}{|l|}{ ASA class } \\
\hline I & 0 \\
\hline II & $2(9.1)$ \\
\hline III & $16(72.7)$ \\
\hline IV & 4 (18.2) \\
\hline V & 0 \\
\hline \multicolumn{2}{|l|}{ ASIA grade } \\
\hline A & 0 \\
\hline$B$ & 0 \\
\hline C & $2(9.1)$ \\
\hline$D$ & $6(27.3)$ \\
\hline$E$ & $14(63.6)$ \\
\hline \multicolumn{2}{|l|}{ Comorbidity } \\
\hline Cardiovascular disease & $15(68.2)$ \\
\hline Diabetes mellitus & $10(45.4)$ \\
\hline Obesity & $7(31.8)$ \\
\hline Respiratory disease & $6(27.3)$ \\
\hline Smoking & $5(22.7)$ \\
\hline Mean $\mathrm{CCl}$ score & $5.8 \pm 1.7$ \\
\hline \multicolumn{2}{|l|}{ Traumatic mechanism } \\
\hline Domestic activity & $15(68.2)$ \\
\hline Car accident & $4(18.2)$ \\
\hline Work activity & $3(13.6)$ \\
\hline
\end{tabular}

Values represent the number of patients (\%) or mean $\pm \mathrm{SD}$ (range).

There were 7 (31.8\%) females and $15(68.2 \%)$ males. The mean age at the time of surgery was $74.2 \pm 7.3$ years (range 62-84 years). The mean follow-up was $39.2 \pm 17.4$ months (range 14-65 months). The most common comorbidity was cardiovascular disease $(68.2 \%)$, followed by diabetes mellitus (45.4\%), obesity (31.8\%), and respiratory disease $(27.3 \%)$. Five patients $(22.7 \%)$ were smokers. The mean Charlson Comorbidity Index (CCI) score was $5.8 \pm$ 1.7. Two patients $(9.1 \%)$ were classified as American Society of Anesthesiologists (ASA) class II, 16 (72.7\%) as class III, and $4(18.2 \%)$ as class IV. All patients reported mechanical back pain unresponsive to medical treatment, and the ASIA grade was $\mathrm{C}$ in 2 patients $(9.1 \%), \mathrm{D}$ in 6 patients (27.3\%), and $\mathrm{E}$ in 14 patients (63.6\%).

The main traumatic mechanisms were domestic accidents $(68.2 \%)$, followed by car or motorbike accidents (18.2\%) and professional-related injuries (13.6\%). The most frequent fractured level was the thoracolumbar junction at T10-L2 in 17 patients (77.3\%), followed by the thoracic spine at T4-9 in 4 patients $(18.2 \%)$ and the lumbar spine at L3-5 in 1 patient (4.5\%).

The mean surgery duration was $78.7 \pm 29.4$ minutes
TABLE 2. Operative characteristics

\begin{tabular}{lc}
\hline & Value \\
\hline \multicolumn{2}{l}{ Fracture level } \\
\hline Thoracic (T4-9) & $4(18.2)$ \\
\hline Thoracolumbar junction (T10-L2) & $17(77.3)$ \\
\hline Lumbar (L3-5) & $1(4.5)$ \\
\hline Complications & 0 \\
\hline Major & $2(9.1)$ \\
\hline Minor & $1(4.5)$ \\
\hline Reop rate & $38.7 \pm 29.4(60-170)$ \\
\hline Mean op duration, mins & $2(2-30)$ \\
\hline Mean LOS, days & $98.9 \pm 36.7(50-240)$ \\
\hline Mean time to postop mobilization, days
\end{tabular}

$\mathrm{EBL}=$ estimated blood loss; $\mathrm{LOS}$ = length of stay.

Values represent the number of patients (\%) or mean \pm SD (range) unless indicated otherwise.

(range 60-170 minutes), with a mean estimated blood loss of $98.9 \pm 36.7 \mathrm{ml}$ (range $50-240 \mathrm{ml}$ ). The mean hospital length of stay was 3 days $(2.6 \pm 3.6$ days [range 3-20 days]) and the mean time to postoperative mobilization was 2 days $(1.5 \pm 3.1$ days [range $2-30$ days]). No intraoperative complications were recorded. Fourteen patients (63.6\%) were discharged to home, and $36.4 \%$ of patients were discharged to a rehabilitation unit. Patient demographic and operative characteristics are summarized in Tables 1 and 2 .

\section{Clinical and Radiological Outcomes}

Comparing the mean preoperative and last followup values, significative improvement was found in VAS scores $(8.4 \pm 1.1$ to $2.8 \pm 0.8, \mathrm{p}<0.001)$. The mean ODI score at 6 weeks $(24.4 \pm 6.1)$ improved to $18.7 \pm 5.8(\mathrm{p}=$ $0.003)$ at the last follow-up, and the mean NMS (6.4 \pm 1.4 to $7.5 \pm 1.6, p=0.02$ ) showed good clinical outcomes with no disability and autonomous mobility during follow-up. The ASIA grade improved in 6 patients (75\%) with neurological deficits and remained unchanged in 2 patients (25\%) (Table 3).

Bone union was observed in all patients. Three of the $176(1.7 \%)$ implanted screws had a pedicle breach $>2 \mathrm{~mm}$ ( $\geq$ grade $\mathrm{C}$ ); however, none of the screws were replaced. In 2 patients $(9.1 \%)$, asymptomatic cement leakage was observed.

The Cobb angle (mean preoperative $5.2^{\circ} \pm 2.9^{\circ}$ to $4.4^{\circ}$ $\pm 3.3^{\circ}$ at follow-up) and SI (mean preoperative $7.9^{\circ} \pm 4.2^{\circ}$ to $8.8^{\circ} \pm 5.1^{\circ}$ at follow-up) had been maintained at followup, showing no loss of segmental kyphosis. An illustrative case is presented in Fig. 1.

\section{Complications and Reoperation Rate}

No major complications were registered perioperatively or during follow-up. Two minor complications were observed; 2 patients $(9.1 \%)$ had a superficial wound infection with complete resolution within 2 weeks after surgery. 
TABLE 3. Clinical outcomes

\begin{tabular}{lc}
\hline & Value \\
\hline VAS score & \\
\hline Preop & $8.4 \pm 1.1$ \\
\hline Postop (6 wks) & $3.6 \pm 1.0$ \\
\hline Follow-up & $2.8 \pm 0.8$ \\
\hline p value (preop vs follow-up) & $<0.001$ \\
\hline ODI score & NA \\
\hline Preop & $24.4 \pm 6.1$ \\
\hline Postop (6 wks) & $18.7 \pm 5.8$ \\
\hline Follow-up & 0.003 \\
\hline p value (postop vs follow-up) & NA \\
\hline NMS & $6.4 \pm 1.4$ \\
\hline Preop & $7.5 \pm 1.6$ \\
\hline Postop (6 wks) & $\mathbf{0 . 0 2}$ \\
\hline Follow-up & \\
\hline p value (postop vs follow-up) & $6(75)$ \\
\hline ASIA grade & $2(25)$ \\
\hline Improved & 0 \\
\hline Unchanged & \\
\hline Deteriorated & \\
\hline
\end{tabular}

NA = not applicable.

Values represent the number of patients (\%) or mean \pm SD unless indicated otherwise. Boldface type indicates statistical significance.

One patient $(4.5 \%)$ required reoperation for implant failure during follow-up; a 74-year-old female who underwent T10-L2 instrumentation for a T12 fracture and cement augmentation whose implant was not placed correctly because of leakage in T10. Due to recurrence of back pain, a lateral radiograph was obtained 2 months after surgery and showed a pullout of the right T10 screw and an extension of instrumentation to T9 where cement augmentation was performed.

\section{Discussion}

A consensus on the preferred management of TL fractures in patients with ankylosed spine disorders is still missing; this is due to high technical variability, surgeon personal experience, and institutional protocols. Although a few studies have reported on nonoperative management for treatment of these injuries, conservative treatment has led to poor outcomes with relevant spinal malalignment and instability resulting in intractable pain and neurological deficits.

Historically, hyperextension AS fractures have been treated using open posterior fusion techniques. However, newer instrumentation systems and surgical strategies, such as percutaneous instrumentation, have been providing similar clinical and radiological outcomes, eventually representing useful and effective alternatives. ${ }^{15-17}$ Recent advances in MIS techniques and development of even newer instrumentation systems have been progressively revolutionizing spine surgery worldwide..$^{23-27}$ Furthermore, the frequency of the use of cement-augmented screws has recently increased, providing higher stability of the construct and reducing chances for implant failure. ${ }^{28,29}$

Our results confirm data from the pertinent literature, in terms of good surgical, clinical, and radiological outcomes after percutaneous instrumentation for hyperextension TL fractures in the ankylosed spine. ${ }^{16,30-33}$ In the present series, surgery provided significative pain relief (with a mean VAS score from $8.4 \pm 1.1$ preoperatively to 2.8 \pm 0.8 at the last follow-up, $\mathrm{p}<0.001$ ), along with lower disability grades and autonomous mobility. Furthermore, of the 8 patients with neurological deficits, ASIA grades improved in 6 (75\%) and remained unchanged in $2(25 \%)$.
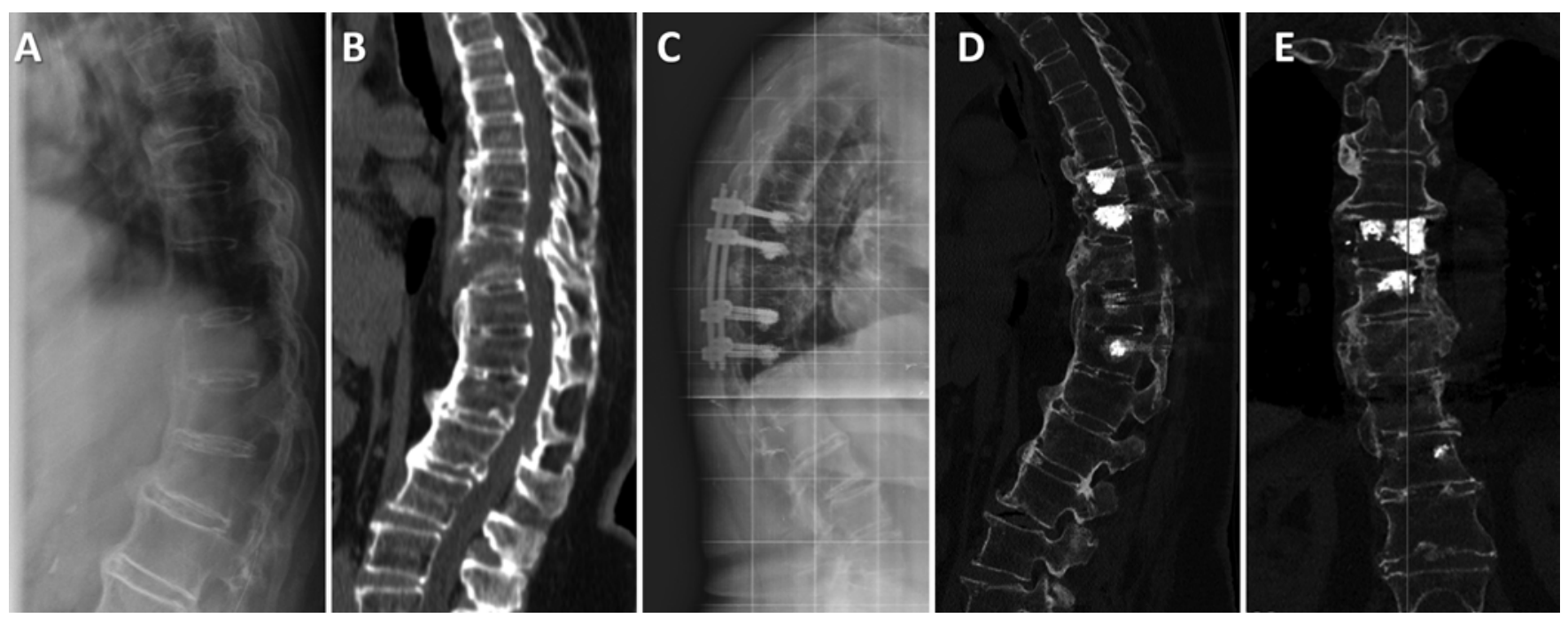

FIG. 1. A 74-year-old patient with a diagnosis of a type B3 T9 fracture who had neurological deficits (ASIA grade D). Preoperative lateral radiograph (A) and sagittal CT scan (B) showing a hyperextension T9 fracture. Postoperative lateral radiograph (C) and sagittal (D) and coronal (E) CT scans at the 1-year follow-up showing percutaneous fixation with cement augmentation, a miniopen posterior decompression, and bone union. 
Evaluation of radiological parameters demonstrated that the Cobb angle and SI were maintained over the follow-up with no loss of kyphosis, as a matter of proof of segmental stability.

In our opinion, in neurologically intact patients, the goals of treatment are spine realignment and a long-term, stable construct providing bone union, while the role of segmental fusion should be critically evaluated. Additionally, the use of cement augmentation should be preferred, due to the high association of osteoporosis in patients with $\mathrm{AS}$, since it decreases the risk of screw loosening and pullout. Moreover, in patients with neurological deficits, a mini-open decompression is associated with neurological improvement, decreased surgical duration, and less intraoperative bleeding.

In terms of complications, our data show that percutaneous instrumentation for AS fractures result in relatively low complication and reoperation rates. We registered 2 minor complications in 2 patients $(9.1 \%)$ with superficial wound infections. The reoperation rate was $4.5 \%$ (1 patient had a screw pullout). Our results confirm data from the few pertinent studies in terms of the low complication rate associated with MIS techniques., ${ }^{7,153}$ Surgery decreases the frequency of complications and reduces the mortality rate to $23 \%$ compared with $51 \%$ with nonoperative treatment. ${ }^{7,32}$ Nevertheless, postoperative complications remain common. Westerveld et al. reported that more than $85 \%$ of patients with AS who underwent surgery experienced at least 1 pulmonary or infectious postoperative complication. ${ }^{13}$ Moreover, in the literature, a $14 \%$ infection rate and a rate of screw loosening from $10 \%$ to $15 \%$ has been reported after open surgery.,11 Percutaneous surgery substantially decreases the risk of infection and cement augmentation reduces the risk of screw loosening.

\section{Study Limitations}

There are few limitations to be disclosed. The present investigation consists of a single-center, retrospective study, which must be considered for a proper data interpretation. Additionally, our study included a small cohort of patients without a control group, which may influence the relevance of our results, and several complications and implant failures could have been consequently unrecognized.

\section{Conclusions}

Percutaneous instrumentation showed good clinical and radiological outcomes, along with relatively low complication and reoperation rates, in the management of hyperextension TL fractures. Accordingly, MIS reduces morbidity and mortality rates and could be considered the preferred treatment for these injuries of the ankylosed spine.

\section{References}

1. Braun J, Sieper J. Ankylosing spondylitis. Lancet. 2007; 369(9570):1379-1390.

2. Feldtkeller E, Vosse D, Geusens P, van der Linden S. Prevalence and annual incidence of vertebral fractures in patients with ankylosing spondylitis. Rheumatol Int. 2006;26(3):234-239.
3. Feldtkeller E, Khan MA, van der Heijde D, van der Linden $\mathrm{S}$, Braun J. Age at disease onset and diagnosis delay in HLAB27 negative vs. positive patients with ankylosing spondylitis. Rheumatol Int. 2003;23(2):61-66.

4. Donnelly S, Doyle DV, Denton A, Rolfe I, McCloskey EV, Spector TD. Bone mineral density and vertebral compression fracture rates in ankylosing spondylitis. Ann Rheum Dis. 1994;53(2):117-121.

5. Vosse D, Feldtkeller E, Erlendsson J, Geusens P, van der Linden S. Clinical vertebral fractures in patients with ankylosing spondylitis. J Rheumatol. 2004;31(10):1981-1985.

6. Vaccaro AR, Oner C, Kepler CK, Dvorak M, Schnake K, Bellabarba C, et al. AOSpine thoracolumbar spine injury classification system: fracture description, neurological status, and key modifiers. Spine (Phila Pa 1976). 2013;38(23): 2028-2037.

7. Caron T, Bransford R, Nguyen Q, Agel J, Chapman J, Bellabarba C. Spine fractures in patients with ankylosing spinal disorders. Spine (Phila Pa 1976). 2010;35(11):E458-E464.

8. Lukasiewicz AM, Bohl DD, Varthi AG, Basques BA, Webb ML, Samuel AM, Grauer JN. Spinal fracture in patients with ankylosing spondylitis: cohort definition, distribution of injuries, and hospital outcomes. Spine (Phila Pa 1976). 2016; 41(3):191-196.

9. Westerveld LA, Verlaan JJ, Oner FC. Spinal fractures in patients with ankylosing spinal disorders: a systematic review of the literature on treatment, neurological status and complications. Eur Spine J. 2009;18(2):145-156.

10. Verlaan JJ, Diekerhof CH, Buskens E, van der Tweel I, Verbout AJ, Dhert WJ, Oner FC. Surgical treatment of traumatic fractures of the thoracic and lumbar spine: a systematic review of the literature on techniques, complications, and outcome. Spine (Phila Pa 1976). 2004;29(7):803-814.

11. Backhaus M, Citak M, Kälicke T, Sobottke R, Russe O, Meindl R, et al. Spine fractures in patients with ankylosing spondylitis: an analysis of 129 fractures after surgical treatment. Article in German. Orthopade. 2011;40(10):917-920, 922-924.

12. Whang PG, Goldberg G, Lawrence JP, Hong J, Harrop JS, Anderson DG, et al. The management of spinal injuries in patients with ankylosing spondylitis or diffuse idiopathic skeletal hyperostosis: a comparison of treatment methods and clinical outcomes. J Spinal Disord Tech. 2009;22(2):77-85.

13. Westerveld LA, van Bemmel JC, Dhert WJA, Oner FC, Verlaan JJ. Clinical outcome after traumatic spinal fractures in patients with ankylosing spinal disorders compared with control patients. Spine J. 2014;14(5):729-740.

14. Choi D. Fractures in ankylosing disorders of the spine: easy to miss and high risk of deterioration. World Neurosurg. 2015;83(6):1029-1031.

15. Nayak NR, Pisapia JM, Abdullah KG, Schuster JM. Minimally invasive surgery for traumatic fractures in ankylosing spinal diseases. Global Spine J. 2015;5(4):266-273.

16. Yeoh D, Moffatt T, Karmani S. Good outcomes of percutaneous fixation of spinal fractures in ankylosing spinal disorders. Injury. 2014;45(10):1534-1538.

17. Krüger A, Frink M, Oberkircher L, El-Zayat BF, Ruchholtz $\mathrm{S}$, Lechler P. Percutaneous dorsal instrumentation for thoracolumbar extension-distraction fractures in patients with ankylosing spinal disorders: a case series. Spine J. 2014;14(12): 2897-2904.

18. van der Linden S, Valkenburg HA, Cats A. Evaluation of diagnostic criteria for ankylosing spondylitis. A proposal for modification of the New York criteria. Arthritis Rheum. 1984;27(4):361-368.

19. Parker MJ, Palmer CR. A new mobility score for predicting mortality after hip fracture. J Bone Joint Surg Br. 1993;75(5): 797-798.

20. Keynan O, Fisher CG, Vaccaro A, Fehlings MG, Oner FC, 
Dietz J, et al. Radiographic measurement parameters in thoracolumbar fractures: a systematic review and consensus statement of the spine trauma study group. Spine (Phila Pa 1976). 2006;31(5):E156-E165.

21. Farcy JPC, Weidenbaum M, Glassman SD. Sagittal index in management of thoracolumbar burst fractures. Spine (Phila Pa 1976). 1990;15(9):958-965.

22. Gertzbein SD, Robbins SE. Accuracy of pedicular screw placement in vivo. Spine (Phila Pa 1976). 1990;15(1):11-14.

23. Blondel B, Fuentes S, Tropiano P, Roche P, Métellus P, Dufour H. Systems for long-segment percutaneous spinal fixation: technical feasibility for various indications. Acta Neurochir (Wien). 2011;153(5):985-991.

24. Dhall SS, Wadhwa R, Wang MY, Tien-Smith A, Mummaneni PV. Traumatic thoracolumbar spinal injury: an algorithm for minimally invasive surgical management. Neurosurg Focus. 2014;37(1):E9.

25. Trungu S, Forcato S, Bruzzaniti P, Fraschetti F, Miscusi M, Cimatti M, Raco A. Minimally invasive surgery for the treatment of traumatic monosegmental thoracolumbar burst fractures: clinical and radiologic outcomes of 144 patients with a 6-year follow-up comparing two groups with or without intermediate screw. Clin Spine Surg. 2019;32(4):E171-E176.

26. Jaikumar S, Kim DH, Kam AC. History of minimally invasive spine surgery. Neurosurgery. 2002;51(5)(suppl):S1-S14.

27. Pietrantonio A, Trungu S, Famà I, Forcato S, Miscusi M, Raco A. Long-term clinical outcomes after bilateral laminotomy or total laminectomy for lumbar spinal stenosis: a single-institution experience. Neurosurg Focus. 2019;46(5):E2.

28. Reinhold M, Knop C, Kneitz C, Disch A. Spine fractures in ankylosing diseases: recommendations of the Spine Section of the German Society for Orthopaedics and Trauma (DGOU). Global Spine J. 2018;8(2)(suppl):56S-68S.

29. Pesenti S, Graillon T, Mansouri N, Adetchessi T, Tropiano P, Blondel B, Fuentes S. Use of pedicle percutaneous cemented screws in the management of patients with poor bone stock. Article in French. Neurochirurgie. 2016;62(6):306-311.

30. Sedney CL, Daffner SD, Obafemi-Afolabi A, Gelb D, Ludwig S, Emery SE, France JC. A comparison of open and percutaneous techniques in the operative fixation of spinal fractures associated with ankylosing spinal disorders. Int $J$ Spine Surg. 2016;10:23.
31. Moussallem CD, McCutcheon BA, Clarke MJ, Cui Q, Currier $\mathrm{BL}$, Yaszemski MJ, et al. Perioperative complications in open versus percutaneous treatment of spinal fractures in patients with an ankylosed spine. J Clin Neurosci. 2016;30:88-92.

32. Robinson Y, Willander J, Olerud C. Surgical stabilization improves survival of spinal fractures related to ankylosing spondylitis. Spine (Phila Pa 1976). 2015;40(21):1697-1702.

33. Schiefer TK, Milligan BD, Bracken CD, Jacob JT, Krauss WE, Pichelmann MA, Clarke MJ. In-hospital neurologic deterioration following fractures of the ankylosed spine: a single-institution experience. World Neurosurg. 2015;83(5):775-783.

34. Bredin S, Fabre-Aubrespy M, Blondel B, Falguières J, Schuller S, Walter A, et al. Percutaneous surgery for thoraco-lumbar fractures in ankylosing spondylitis: Study of 31 patients. Orthop Traumatol Surg Res. 2017;103(8):1235-1239.

\section{Disclosures}

The authors report no conflict of interest concerning the materials or methods used in this study or the findings specified in this paper.

\section{Author Contributions}

Conception and design: Trungu, Miscusi, Raco. Acquisition of data: Trungu, Ricciardi, Forcato. Analysis and interpretation of data: Trungu, Forcato. Drafting the article: Trungu, Ricciardi. Critically revising the article: Ricciardi, Raco. Reviewed submitted version of manuscript: Miscusi, Raco. Approved the final version of the manuscript on behalf of all authors: Trungu. Statistical analysis: Ricciardi. Administrative/technical/material support: Forcato. Study supervision: Miscusi, Raco.

\section{Correspondence}

Sokol Trungu: "Sapienza" University of Rome, Sant'Andrea Hospital, Rome, Italy. s_trungu@hotmail.com. 